\title{
Case Study in Systematic Design Engineering - Bow Thruster COVERS
}

\author{
W. Ernst Eder \\ Professor Emeritus, Dr.h.c., Royal Military College of Canada (retired) \\ eder-e@kos.net
}

\begin{abstract}
Students learning design engineering at times need a good example of procedure for novel design engineering. The systematic heuristic-strategic use of a theory to guide the design process - Engineering Design Science - and the methodical design process followed in this case study is only necessary in limited situations. The full procedure should be learned, such that the student can select appropriate parts for other applications.

Creativity is usually characterized by a wide search for solutions, especially those that are innovative. The search can be helped by this systematic and methodical approach.

This case example is presented to show application of the recommended method, and the expected scope of the output, with emphasis on the stages of conceptualizing. The case follows a novel design problem of a mechanism to open and close the bow thruster covers for the Caravan Stage Barge.
\end{abstract}

Keywords: Systematic design engineering, theory-based method, worked case example.

\section{INTRODUCTION}

Students learning design engineering at times need a good example of procedure for novel design engineering. The systematic and methodical design process followed in this case study is abridged from [1][2]. As shown in a paper presented at a previous conference [3], such a fully systematic procedure is only necessary in limited situations, when an engineering designer is faced with an unfamiliar and non-routine situation. Systematic design engineering as a procedure is the heuristic-strategic use of a theory to guide the design process - Engineering Design Science [1][2][4] is recommended as guiding theory. Methodical design engineering as a procedure is the heuristic use of newly developed and established methods within the engineering design process, including theory-based and 'industry best practice', strategic and tactical, formalized and intuitive methods. Systematic and methodical procedures have a substantial overlap, but are not co-incident. The full procedure should be learned, such that the student can select appropriate parts for other applications.

Creativity [5] is usually characterized by a wide search for solutions, especially those that are innovative. This search can be supported by the recommended systematic and methodical approach. All generated alternatives should be kept on record, to allow re-tracing and recovery from subsequent detection of a better alternative. Each step in the overall procedure should be concluded by selecting the most appropriate (one or two) solutions for further processing, in order to control a tendency towards 'combinatorial complexity'.

The first case study, systematic according to the state of the theory and method at that time, appeared in 1976 [6] - a machine vice. The second appeared in 1980 [7] - a welding positioner. The next three, also systematic, were published in 1981 in German - a riveting fixture, a milling jig, and a powder-coating machine. The third set was published in 1983 - a P-V-T-experiment, a hand winding machine for tapes, and a tea brewing machine the first two were systematic, the third took an industrialartistic design approach. An English edition was published in 1988 [8], and included the existing six case studies, plus two new items - a wave-powered bilge pump, and an oil drain valve - and again the bilge pump only loosely followed the systematic method. Three further case studies were published in 2008 [2] - the tea machine revised to current systematic procedures showing enhanced engineering information; re-design of a water valve; and an electro-static smoke gas dust precipitator, with rapper for dust removal [9]. The currently last three case examples were published in 2010 [2] - a trapeze demonstration rig [12], re-design of an automotive oil pump [13], and a hospital emergency bed, with compensation devices for the support arrangement. Two other cases have now been prepared for the International Conference DESIGN 2012 [14][15], both from the Caravan Stage Barge [16] which has been in operation in Canadian and U.S.A. coastal waters, and now in the Mediterranean, since 1995. 
The primary purpose of these case studies is to present examples for procedural application of the recommended engineering design method that students and practitioners can follow and study to help learn the scope of the method and its models. This purpose has been applied in courses at the Eidgenössische Technische Hochschule (ETH) by Dr. Vladimir Hubka (1976-2000), at The Royal Military College of Canada (1981-2006), and at the University of West Bohemia (1990-present) - for all levels of education and for industry consultations. A secondary purpose was to verify and validate the theory and its models, and the method derived from the theory. The emphasis in all case studies was on the engineering design procedure and use of the models, the chosen technical systems in several case studies were not necessarily optimal.

The systematic procedure must be adapted to the problem. The cases demonstrate that an engineering designer can idiosyncratically interpret the models to suit the problem, and develop information in consultation with a sponsor. Opinions will vary about whether a requirement should be stated in the class of properties as shown, or would be appropriate in a different class.

This case example is presented to show application of the recommended method, and the expected scope of the output, with emphasis on the stages of conceptualizing. The embodying/laying out and detailing stage is regarded as more routine.

The international standard ISO 9000:2005 defines two sorts of technological, artificial, human-made systems:

- process systems, consisting of operations transformation process (TrfP) transforming an operand;

- tangible object systems, consisting of (tangible) constructional parts, with organs and functions technical systems (TS), if they have substantial engineering content.

Figure 1 shows the basic model on which the theory and method are based. This model of the transformation system declares:

An operand (materials, energy, information, and/or living things - M, E, I, L) in state Od1 is transformed into state Od2, using the active and reactive effects (in the form of materials, energy and/or information - $M$, E, I) exerted continuously, intermittently or instantaneously by the operators (human systems, technical systems, active and reactive environment, information systems, and management systems, as outputs from their internal processes), by applying a suitable technology $\mathrm{Tg}$ (which mediates the exchange of $\mathrm{M}, \mathrm{E}$, I between effects and operand), whereby assisting inputs are needed, and secondary inputs and outputs can occur for the operand and for the operators.

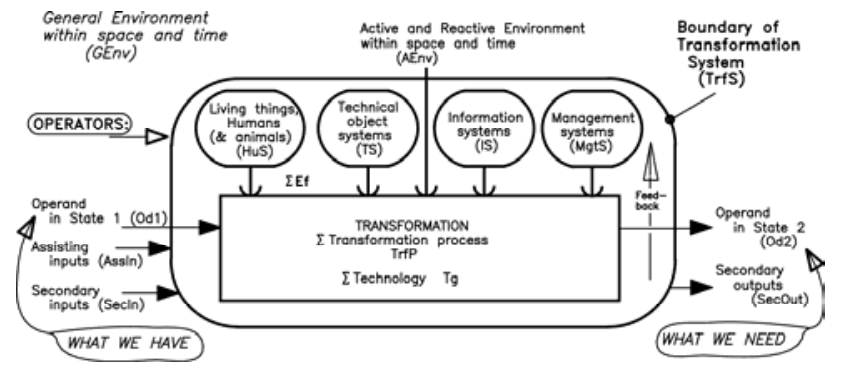

Figure 1 General Model of a Transformation System [1][2]

Using this model as basis, the stages and steps of a novel design process [1][2] are summarized as:

- task defining:

(P1) establish a design specification for the required system, a list of requirements;

(P2) establish a plan and timeline for design engineering; - conceptualizing

(P3a) from the desirable and required output (operand in state Od2), establish a suitable transformation process $\operatorname{TrfP}(\mathrm{s})$,

(P3.1.1) if needed, establish the appropriate input (operand in state Od1);

(P3.1.2) decide which of the operations in the TrfP(s) will be performed by technical systems, TS, alone or in mutual cooperation with other operators; and which TS(s) (or parts of them) need to be designed;

(P3.1.3) establish a technology (structure, with alternatives) for that transformation operation, and therefore the effects (as outputs) needed from the technical system;

(P3b) establish what the technical system needs to be able to do (its internal and cross-boundary functions, with alternatives);

(P4) establish what organs (function-carriers in principle and their structure, with alternatives) can perform these functions. These organs can be found mainly in prior art, especially the machine elements, in a revised arrangement as proposed by Weber [17][18][19];

- embodying/laying out and detailing:

(P5a) establish what constructional parts and their arrangement are needed, in sketch-outline, in rough layout, with alternatives;

(P5b) establish what constructional parts are needed, in dimensional-definitive layout, with alternatives;

(P6) establish what constructional parts are needed, in detail and assembly drawings, with alternatives.

The suffix ' (s)' indicates that this $\operatorname{TrfP}(\mathrm{s})$ and/or TS(s)

is the subject of interest. Only those parts of this engineering design process that are thought to be useful are employed. Such an 'idealized' procedure cannot be accomplished in a linear fashion - iterative and recursive working is essential, using analysis and synthesis [20]. 
PROCEDURAL NOTE: Compare the output of each stage with the theoretical figures from [1][2] to check whether any important elements may be missing. Procedural notes such as this may be interspersed with the case to explain some aspects of the procedure.

\section{CASE STUDY - BOW THRUSTER COVERS}

Founded in 1970, the Caravan Stage Company [16] travelled in Canada and the U.S.A. from place to place, entered a community with horse-drawn gipsy-style caravan carriages, pitched a large (24 $\mathrm{m}$ diameter) decorated tent in a park, and using the caravans in the tent as their scenery performed self-scripted plays. Around 1992 they decided to have a steel replica of a wooden River Thames (London, England) sailing barge designed and fabricated in a small dockyard in Kingston, Ontario, Canada. The Thames sailing barges were intended to carry bulk goods such as coal along coastal waters (from Newcastle-on-Tyne to London). The stage barge took four years to complete, $30 \mathrm{~m}$ length, $7.2 \mathrm{~m}$ beam, $1.3 \mathrm{~m}$ draft, single mast, fore-and-aft rigged sails, $316 \mathrm{~m}^{2}$ sail area, about 90 tonne displacement. All materials and OEM parts were donated to the Caravan Stage Company for that purpose, about $\mathrm{Cdn} \$ 2,000,000.00$. The newly designed superstructure, mast and rigging were intended as the stage for performances, with the audience on shore. The stage barge was intended to be fully independent, with its own power supply (two diesel motors), lighting and sound system, galley and sleeping accommodation, etc.

Ships at times need a lateral force to depart from a mooring location at a jetty. This is often performed by a cross-wise tunnel at the bow which contains an auxiliary propeller driven (reversibly) from within the hull. To avoid extra drag on the hull during forward motion of the ship, this tunnel is usually covered at both ends - covers that must be opened for the bow thruster to operate.

The author was initially contacted in 1994 by Paul Kirby, producer of the Caravan Stage Company, via the Head of Mechanical Engineering, The Royal Military College of Canada (RMC) to help by designing various needed items. Among these (in 1996) was an arrangement to open and close the bow thruster covers from an inboard-mounted hydraulic motor.

Steps from the procedural model [1][2 (figure 11.1, p. 219-222)] were considered, and the following review cycle was applied for each step:

\{Improve, optimize $\}-<$ Substantiate, evaluate, select, decide $>-\{$ Verify, check, reflect $\}$

- task defining:

(P1) establish a design specification for the required system, a list of requirements;
Requirements are listed only under the most relevant TrfP and/or TS-requirements class as judged by the engineering designer, and cross-referenced if they are repeated in any other relevant requirement class [2 (figure 11.4 , p. 226-227)]. Indication of priority $-\mathrm{F}$... fixed requirement, must be fulfilled; S ... strong wish; W ... wish; $\mathrm{N}$... not considered

Rq1 OrgRq Organization requirements $(\mathrm{Rq} 1 \mathrm{~A}-\mathrm{Rq} 1 \mathrm{E})$

F Design and manufacture by RMC, Dept of Mechanical Engineering.

Rq2 TrfRq Requirements of the Transformation (Rq2A $-\mathrm{Rq} 2 \mathrm{E})$

F Each cover must be opened/closed via a shaft penetrating the thruster tunnel from the top.

F Water ingress from the tunnel to the hull must be prevented.

Rq3 EfRq Effects requirements of the TS (Rq3A $\mathrm{Rq} 3 \mathrm{C})$

F Provide positive stop for cover in closed position.

F Open position of cover should allow maximum water flow.

S Minimum chance of fouling to interfere with opening/closing.

Rq4 MfgRq Manufacturing requirements

F All fabrication in house at RMC Mech. Eng. Dept., or on site at Stage Barge.

Rq5 DiRq Distribution requirements

Rq6 LiqRq Liquidation requirements

$F \quad$ Non-toxic materials

Rq7 HuFRq Human factors requirements (Rq7A Rq7G)

Rq8 TSFRq Requirements of factors of other TS (in their TrfP) (Rq8A - Rq8G)

$\mathrm{F}$ Must not interfere with thruster propeller and drive.

Rq9 EnvFRq Environment factors requirements, LC1 LC7 (Rq9A - Rq9B)

Rq10 ISFRq Information system factors requirements, LC1 - LC7 (Rq10A - Rq10F)

Rq11 MgtFRq Management factors requirements

Rq11A Management planning, LC1

Rq11B Management of design and manufacturing process, LC2 - LC4

Rq11C Design documentation, LC2

$\mathrm{F}$ Original drawings to remain at $\mathrm{RMC}$, copies held by Stage Barge.

Rq11D Situation, LC2

Rq11E Quality system.

Rq11F Information requirements

Rq11G Economic requirements

Rq11H Time requirements

Rq11J Tangible resources

Rq11K Organization 
Rq11L Supply chain requirements

F Obtain donated items before start of detail design: 2 Tides Marine 1" Strong bearing/seals, 8 Rexnord $1 "$ sealed spherical bearings.

Rq11M Other management aspects

DesRq Engineering design requirements for $\operatorname{TrfP}(\mathrm{s})$ and $\mathrm{TS}(\mathrm{s})(\mathrm{Rq} 12-\mathrm{Rq} 14)$

None.

(P2) establish a plan and timeline for design engineering;

Detail design to be completed before end April 1996.

- conceptualizing:

(P3a) from the desirable and required output (operand in state Od2), establish a suitable transformation process $\operatorname{TrfP}(\mathrm{s})$;

(P3.1.1) if needed, establish the appropriate input (operand in state Od1);

(P3.1.2) decide which operations in the $\operatorname{TrfP}(\mathbf{s})$ will be performed by technical systems, TS, alone or in mutual cooperation with other operators; and which TS(s) (or parts of them) need to be designed;

Transformation process see figure 2

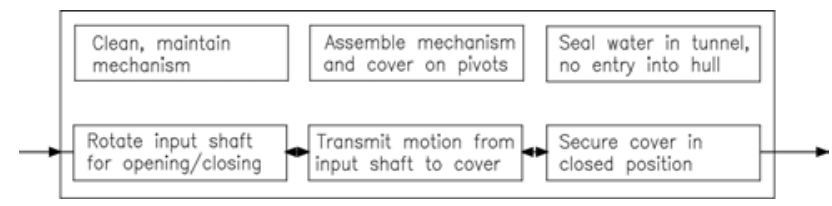

Figure 2 Transformation Process (TrfP) for Thruster Covers

(P3.1.3) establish a technology (structure, with alternatives) for that transformation operation, and therefore the effects (as outputs) needed from the technical system;

Available technology alternatives see figure 3. The most promising with least difficulties appears to be 'horizontal pivot', in view of the change of hull slope across the tunnel mouth. The angle of rotation from 'closed' to 'open' is yet to be established.

Sizes of the thruster tunnel were obtained from the Stage Barge. The most favourable cover pivot position and opening angle were graphically investigated, see figure 4 .

(P3b) establish what the technical system needs to be able to do (its internal and cross-boundary functions, with alternatives);

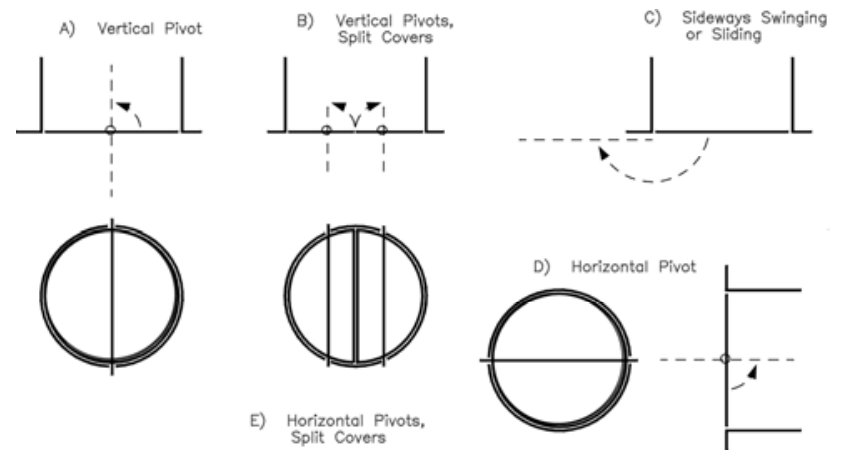

Figure 3 Technologies for Thruster Cover Action
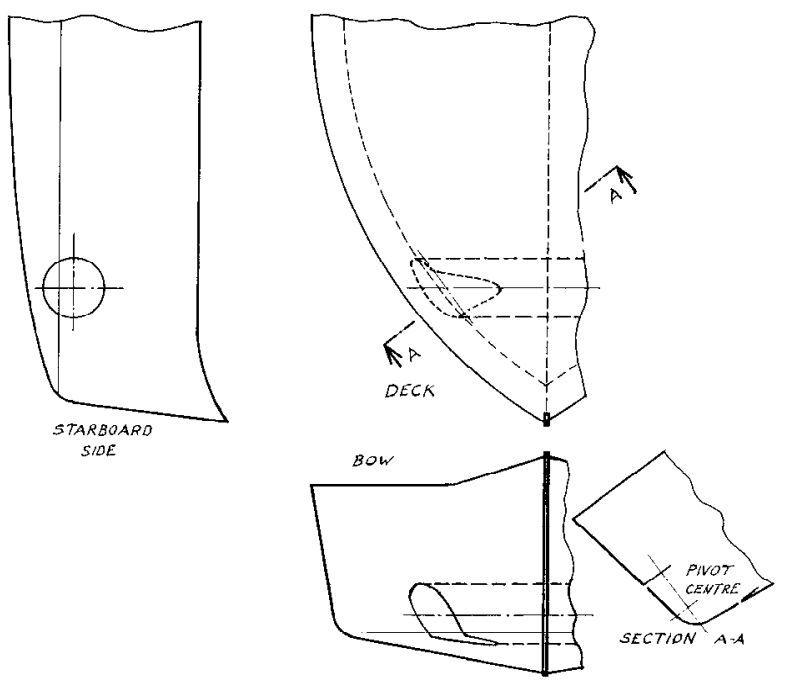

Figure 4 Bow Thruster Tunnel - Geometry and Cover Motion

The TS-function structure developed for this project is shown in figure 5. Most of these TS-functions are solvable by routine means. The numbered functions are variable, and therefore used in a morphological matrix.

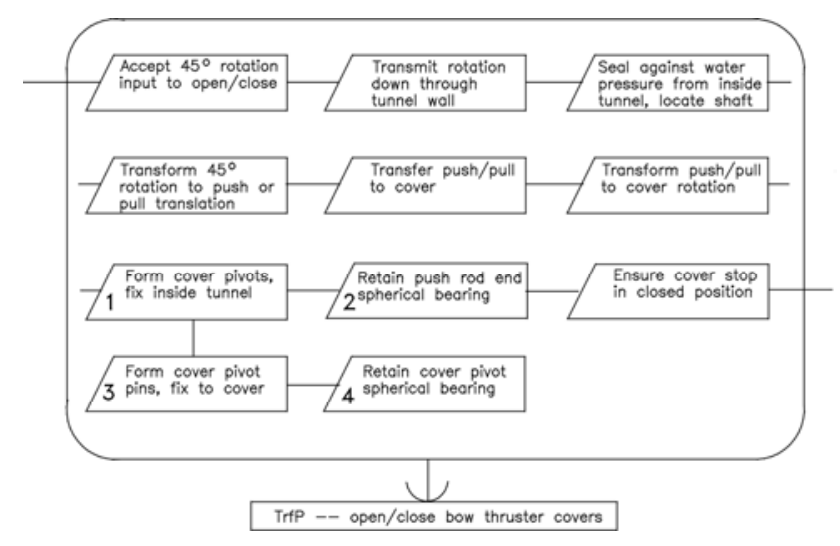

Figure 5 TS-Function Structure for Bow Thruster Covers 
(P4) establish what organs (function-carriers in principle and their structure, with alternatives) can perform these functions;

Figure 6 shows a morphological matrix, and figure 7 shows the selected TS-organ structure.

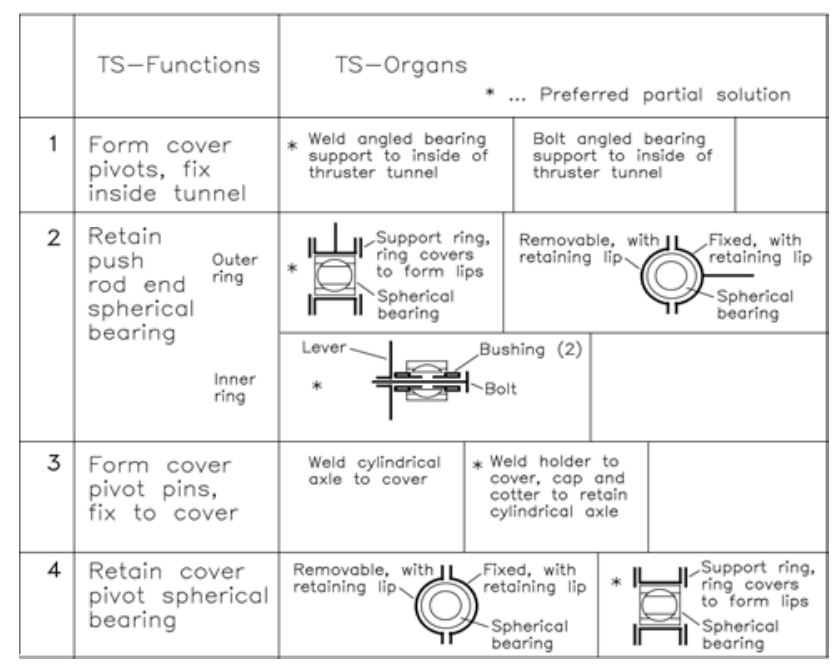

Figure 6 Morphological Matrix for Bow Thruster Covers

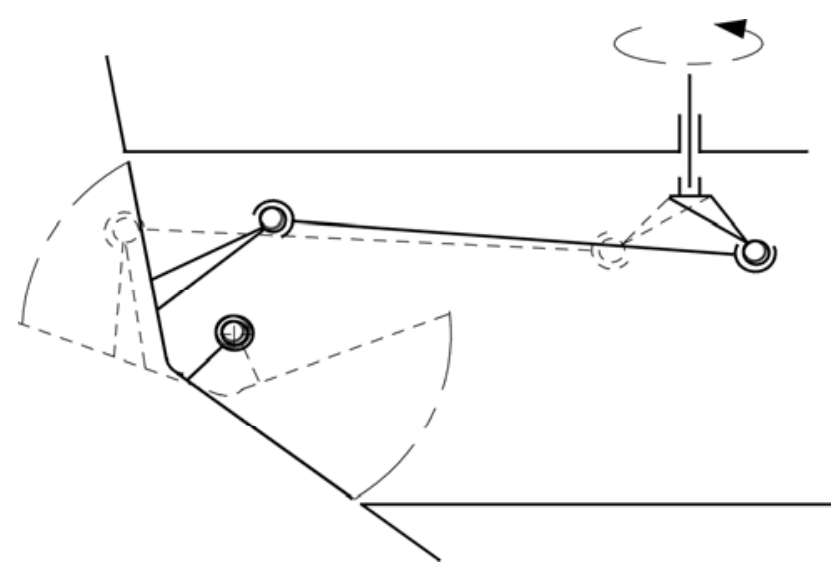

Figure 7 TS-Organ Structure for Bow Thruster Covers

- embodying/laying out and detailing:

(P5a) establish what constructional parts and their arrangement are needed, in sketch-outline, in rough layout, with alternatives;

(P5b) establish what constructional parts are needed, in dimensional-definitive layout, with alternatives; (P6) establish what constructional parts are needed, in detail and assembly drawings, with alternatives.

A sample detail drawing (pencil on paper) is shown in figure 8 . In this case, because these drawings are unlikely to be reused, pencil-on-paper were adequate.

\section{CLOSURE}

The prescribed length of paper does not allow a fuller discussion of the recommended method, but see [1][2]. A more experienced engineering designer will no doubt be able to reach a similar result whilst neglecting one or more of the earlier of these formal steps and models.

\section{References}

[1] Eder, W.E. and Hosnedl, S (2008) Design Engineering: A Manual for Enhanced Creativity, Boca Raton: CRCPress

[2] Eder, W.E. and Hosnedl, S. (2010) Introduction to Design Engineering - Systematic Creativity and Management, Leiden (The Netherlands): CRC Press / Balkema (in press)

[3] Eder, W.E. (2009) 'Why Systematic Design Engineering?' in Proc. $6^{\text {th }}$ Symposium on International Design and Design Education, August 30 - September 2, 2009, San Diego, California, USA, New York: ASME, paper number DETC2009-86067

[4] Hubka, V., \& Eder, W.E. (1996) Design Science: Introduction to the Needs, Scope and Organization of Engineering Design Knowledge, London: SpringerVerlag, http://deseng.ryerson.ca/DesignScience/

[5] Eder, W.E. (ed.) (1996) WDK 24 - EDC - Engineering Design and Creativity - Proceedings of the Workshop EDC, Pilsen, Czech Republic, November 1995, Zürich: Heurista

[6] Eder, W.E., 'Requirements to Properties - Iterative Problem Solving', in Proc. Canadian Engineering Education Association 2010 Inaugural Conference, 7-9 June 2010, Queen's University, Kingston, ON

[7] Hubka, V. (1976) Theorie der Konstruktionsprozesse (Theory of Design Processes), Berlin: Springer-Verlag

[8] Hubka, V. and W.E. Eder (1992) Engineering Design, Zürich: Heurista, $\left(2^{\text {nd }}\right.$ edition of Hubka, V., Principles of Engineering Design, London: Butterworth Scientific, 1982, translated and edited by W.E. Eder from Hubka, V., WDK 1 - Allgemeines Vorgehensmodell des Konstruierens (General Procedural Model of Designing), Zürich, Heurista, 1980; translated into several other languages: French, M. Wyss (1980) Zürich: Heurista; Italian, U. Pighini (1982) Marsilo ed.; Czech, S. Hosnedl (1995) Zürich: Heurista, and others)

[9] Hubka, V., Andreasen, M.M. and Eder, W.E. (1988) Practical Studies in Systematic Design, London: 
Butterworths, (English edition of WDK 4 - Fallbeispiele, Zürich: Heurista, 1981 and 1983)

[10] Eder, W.E., 'Case Study in Design Engineering' in Proc. CDEN 06 Toronto, 24-26 July 2006, on CD-ROM p. $332-338$

[11] Eder, W.E., 'Case Study in Systematic Design Engineering - Smoke Gas Dust Precipitation', paper ASME DETC2009-86069 in Proceedings of the $6^{\text {th }}$ Symposium on International Design and Design Education, DEC 6, August 30 - September 2, 2009, San Diego, California, USA

[12] Eder, W.E., 'Case Study in Systematic Design Engineering - Trapeze Demonstration Rig', paper ASME DETC2010-28065 in Proc. $7^{\text {th }}$ Symposium on International Design and Design Education, DEC 7, 15-18 August 2010, Montreal, Quebec, Canada

[13] Eder, W.E. and Heffernan, P.J., 'A Case Study in Systematic and Methodical Design Engineering', in Proc. CDEN/C2C2 Conference 2009, 27-29 July 2009, McMaster University, Hamilton, ON

[14] Eder, W.E. (2012a) 'Case Example in Systematic Design Engineering - Leeboard Mounting', for Proc. International Design Conference - DESIGN 2012, Dubrovnik - Croatia, May 21-24, 2012
[15] Eder, W.E. (2012b) 'Case Example in Systematic Design Engineering - Propeller Shaft Bearing Arrangement', for Proc. International Design Conference - DESIGN 2012, Dubrovnik - Croatia, May 21-24, 2012 (in review)

[16] http://www.caravanstage.org

[17] Weber, C. and Vajna, S. (1997) 'A New Approach to Design Elements (Machine Elements)'. In Riitahuhta, A. (ed.) WDK 25 - Proc. ICED 97 Tampere, Tampere University, Vol. 3, 1997, p. 685-690

[18] Eder, W.E. (2004) 'Machine Elements - Integration Of Some Proposals', Proc. AEDS 2004 Workshop, The Design Society - AEDS-SIG, 11-12 Nov 2004, Pilsen, Czech Republic, on CD-ROM, http://www.kks.zcu.cz/aeds

[19] Eder, W.E. (2005) 'Machine Elements - Revision and Outlook for Design Education', in Proc. Second CDEN International Conference, University of Calgary, Alberta, 18-19 July 2005 at Kananaskis Resort, paper 10006 on CD-ROM

[20] Eder, W.E. (2008) 'Aspects of Analysis and Synthesis in Design Engineering', in Proc. CDEN 08, Halifax, N.S., 27-29 July 2008, on CD-ROM

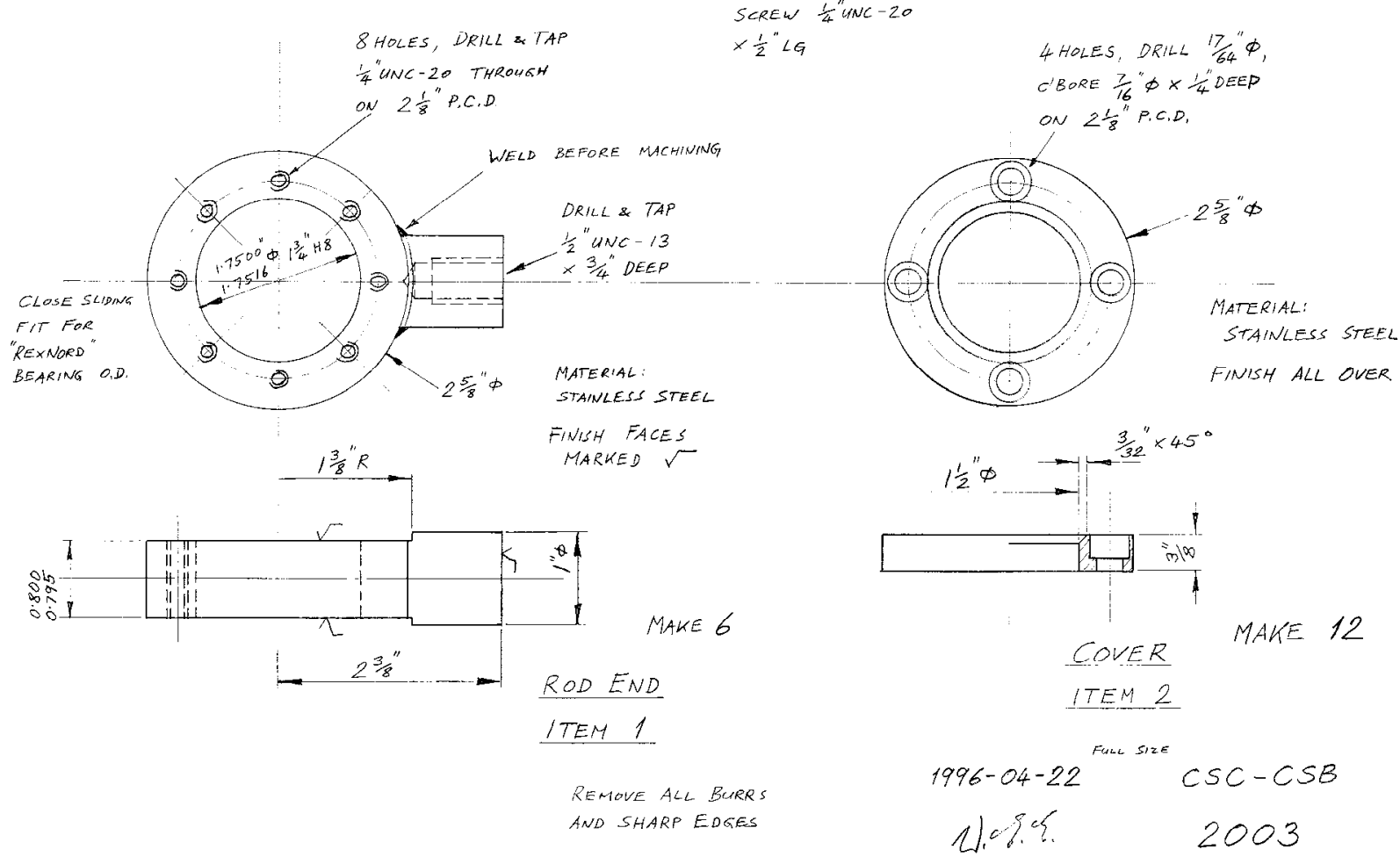

Figure 8 Detail Drawing for Rod Ends, Bow Thruster Cover Mechanism 